\title{
An improved methodology for applying the influence function for subsidence hazard prediction
}

\author{
Ali Saeidi ${ }^{a^{*}}$, Olivier Deck ${ }^{b}$, Mahdiyeh Seifaddini ${ }^{a}$, Marwan AL Heib ${ }^{c}$ and Thierry Verdel ${ }^{b}$ \\ ${ }^{a}$ Department of Applied Sciences, Université du Québec à Chicoutimi, Chicoutimi, QC, G7H \\ 2B1, Canada \\ bUniversité de Lorraine, GeoRessources, UMR 7359, Nancy, F-54042, France \\ ${ }^{\mathrm{c}}$ INERIS, Ecole des Mines de Nancy, UMR 7359, Nancy, F-54042, France \\ *Corresponding author: ali_saeidi@uqac.ca
}

\section{Abstract}

The extraction of ore and minerals by underground mining often presents important risk for surface infrastructures. Several methods that have been developed to predict ground subsidence, and the influence function method (IFM) is one of the most efficient for predicting this phenomenon in the context of mining engineering. However, applying this method to a specific mining site requires adjustments that are difficult to achieve. In this paper, a methodology is proposed for adjusting the IFMs to each mining site. It is shown that the maximum subsidence depends on both the Width(W)/Height(H) and Length(L)/W ratios of mine panel. Moreover, the effect of the length variation becomes negligible for $\mathrm{L} / \mathrm{W}$ ratio values greater than 4 , but it is significant for values around 1. The influence angle of each mine panel has a significant effect on the subsidence, and a variation of $5^{\circ}$ may lead to significant variations in the prediction. A coefficient of dimensions reduction (CDR) used for adjusting the IFM results in each mine panels is used to adjust the value of subsidence above the border of the mine panels. The appropriate influence angle and CDR parameters should be calculated for each mining region. The methodology is validated and tested by two case studies based on National Coal Board (NCB) data from England, and Provence Coal Basin data from France.

Keywords: Mining subsidence, Influence function method, vertical subsidence, influence angle.

\section{Symbol notation list}

$O$ : Opening of mining panel or sector $(\mathrm{m})$

$W$ : Width of mining panel or sector $(\mathrm{m})$

$H$ : Depth of mining panel or sector (m) 
$L$ : Length of mining panel or sector (m)

$K$ : Constant coefficient for determining maximum subsidence

$\tau$ : Extraction ratio for room and pillar mining method

$\gamma:$ Influence angle

$K_{z}$ and IF: Influence function

$S_{\text {max }}$ : Maximum value of the vertical subsidence for critical and super-critical mining surface.

$S_{m}$ : Maximum value of subsidence in the centre of mine panel

$S$ : Value of subsidence at each point of the surface

$d S_{z}$ : Elementary subsidence of a given point in the surface produced by the collapse of an elementary element $\mathrm{dA}$ in the mine

IFM: Influence function method

$C D R$ : Coefficient of dimension reduction

\section{$1 \quad$ Introduction}

The extraction of ore and minerals by underground mining may induce ground subsidence. These phenomena produce several types of ground movement: horizontal and vertical ground displacements, ground curvature and horizontal ground strain at the surface (Deck, Verdel, and Salmon 2009). These movements can cause damage to buildings and infrastructures on the surface and jeopardise the safety of people (Merad et al. 2004). Therefore, predicting ground subsidence is very important in regions with underground mining, and several prediction methods have been developed. These methods can be classified into empirical, semi-empirical, application of Probability Integration Model (Diao et al. 2016) and numerical methods. The empirical and semiempirical methods include graphical methods, profile function methods and influence function methods (Aissaoui 1999).

Numerical methods make use of various methods like the finite element method, the distinct elements method or the finite differences method. These methods can be very accurate when validated, but their application at a specific site and in a certain context is highly dependent on the available data regarding the local geology, the geomechanical properties of the overburden and sub-surface rock/soil. Moreover, calculating a three dimensional prediction of the subsidence 
may require a large computational effort (Coulthard and Dutton 1988; Alejano, RamírezOyanguren, and Taboa 1999).

The Probability Integration Model is widely used for subsidence prediction with coal mining specially for subsidence prediction in longwall mining method. It regards the movement of the sedimentary rock layer as a stochastic process that use the statistical laws, and the probability density function integral equation is used to predict surface subsidence caused by coal mining. This approach is a widely used method for subsidence prediction in China (Diao et al. 2016; Hongdong et al. 2018).

Graphical methods are derived from analysing an extensive field database collected over many years from mining subsidence in one country. A disadvantage of these methods is that they are developed in relation to a specific context and cannot be used with accuracy in other contexts. A well-known example has been developed by the NCB (National Coal Board 1975), which has provided several abacuses that can be used to predict subsidence for simple geometry mines (rectangular).

The profile function methods are based on mathematical functions that have been obtained by a curve fitting procedure to match the predicted profile with observed profiles (Whittaker and Reddish 1989; Haciosmanoglu 2004). Many profile functions are available for subsidence prediction (National Coal Board 1975). These methods suffer from the same disadvantage as the graphical methods: they can be used only in specific contexts (Haciosmanoglu 2004). Another disadvantage is that these methods are developed to predict a two dimensional subsidence profile and are not intended to predict the whole three dimensional subsidence.

Influence function methods (IFMs) were developed by Ren, Reddish and Whittaker (1987) and are used extensively (Haciosmanoglu 2004; Sheorey el al. 2000) to predict mining subsidence. 
They are based on the superposition principle and address the displacements induced by a subsidence at a given point as the sum of the displacements induced by the subsidence of elementary mining units. Different coefficients are suggested to adjust the results of the superposition (Haciosmanoglu 2004; Sheorey el al. 2000), but their exact influence and their choice is sometimes questionable.

Nevertheless, IFMs present several advantages compared to other methods for the three dimensional prediction of subsidence. First, these methods can be used with any type of mine geometry; empirical and semi-empirical methods are restricted to simple geometries. Secondly, these methods can be used to simultaneously assess vertical and horizontal ground movements induced by the subsidence at each point of the surface. In particular, the horizontal ground strain can be calculated everywhere and then used to assess the building damage (Sheorey el al. 2000; Saeidi, Deck, and Verdel 2009, 2012, 2015). An important advantage of IFM is the possibility to conduct a probabilistic evaluation of ground subsidence. The similar application applied for subsidence prediction using profile function methods by Toraño et al. (2000). The probabilistic methods as Mont-Carlo simulation could apply on the IFM methods for probabilistic subsidence prediction. (Saeidi et al. 2009).

The influence function method (IFM) with suitable modifications can be used to predict subsidence for mine panels, even panels with complex geometry. This method is based on the principle of superimposition, which is questionable in the case of the mining subsidence prediction. Indeed, the superposition principle is only valuable for purely linear elastic phenomena, not when important inelastic and nonlinear phenomena occur during subsidence. Therefore, the application of this method to each mining site may require major modifications, such as reducing the mine panel dimensions or changing the influence function and angle. 
In this paper, a methodology is described to adjust influence function methods for any mining site. For this purpose, the principles of IFM are first described with the available strategies for their adjustment. The main parameters of these methods are presented, and the data used for their adjustment are described. In the second part, a sensitivity analysis is performed, and each parameter and strategy for each adjustment is investigated. Finally, a methodology to adjust IFMs is proposed and tested with two case studies.

\section{Presentation of the influence function methods}

\section{General description}

IFMs are based on the principle of superposition. If $\mathrm{s}_{1}$ and $\mathrm{s}_{2}$ are the vertical subsidence of a surface point caused by the collapse, respectively, of the surfaces $A_{1}$ and $A_{2}$ of an underground operation, then the subsidence caused by the collapse of the two surfaces $A_{1}+A_{2}$ is $s_{1}+s_{2}$ (Aissaoui 1999). Assuming an infinitesimal element dA (Figure 1a) at depth $\mathrm{H}$ to be extracted, the element will create an elementary trough at the surface. The deepest point of the trough is located directly above the extraction element $\mathrm{dA}$, and the depth of the trough decreases with the radial distance from the deepest point. Consequently, the subsidence of a point $\mathrm{P}$ can be stated as a function of the radial distance between $\mathrm{P}$ and the trough central point.

The elementary subsidence $\mathrm{dS}_{\mathrm{z}}$ caused by an elementary surface $\mathrm{dA}$ at a point on the surface is calculated with Equation 1.

$$
d S_{z}=S_{\max } \times K_{z}(r) \times d A
$$

Where $\mathrm{S}_{\max }$ is the maximum value of subsidence that can be observed for a critical and super critical case, $\mathrm{K}_{\mathrm{z}}(\mathrm{r})$ is the influence function that will be discussed, $\mathrm{r}$ is the radial distance 
between the surface $\mathrm{dA}$ and the surface point under consideration and $\gamma$ is the influence angle (Figure 1a).

The final vertical subsidence at a given point $\mathrm{P}$ on the surface can then be estimated by integrating Equation 1 over the mine panel surface (A) (Equation 2).

$$
S_{z}=S_{\max } \iint_{A} K_{z} \times d A
$$

An equivalent and frequent calculation considers a cone of influence whose apex is located at the point of the surface considered (Figure 1). In this figure, we consider a point on the surface and calculate the effect of all elements of the mine surface contained in the cone of influence. For example, Figure $1 \mathrm{~b}$ shows the effect of three basic areas of the mine over the point $\mathrm{P}$ on the surface. The influence of the element is maximal for $\mathrm{dA} 1$, which is located in the center of the cone under the point $\mathrm{P}$, the influence of the element $\mathrm{dA} 2$ is less than that of the $\mathrm{dA} 1$, and the $\mathrm{dA} 3$ element has no influence on the point P (Haciosmanoglu 2004). This methodology requires discretising the cone base surface into several rings and sectors (Figure $1 \mathrm{~b}$ and $\mathrm{c}$ ). The number of rings and sectors is chosen after a sensitivity analysis. Both the accuracy of calculations and computation time increase with the number of rings and sectors; Whittaker and Reddish 1989, concluded that 10 rings and 64 sectors $(10 \times 64=640$ elementary surfaces $)$ give satisfactory results to calculate the subsidence. Finally, the calculation of the subsidence for each point $\mathrm{P}$ on the surface requires applying Equation 1 to each of the 640 sectors under the point $\mathrm{P}$ included into the mine area (Haciosmanoglu 2004).

$S=\sum d S$

In conclusion, three necessary parameters must be chosen to use IFM:

- the maximum value of the vertical subsidence in the center of subsidence for critical and super critical cases $\mathrm{S}_{\max }$ 
$\circ$ the influence angle $\gamma$

$\circ$ the influence function $\mathrm{K}_{Z}(\mathrm{r})$

These parameters may be adjusted to improve the accuracy of the results and to take into account that conditions for application of the superposition principle are not respected. In particular, a frequent adjustment is reducing the mine dimensions taken into account for the prediction (Haciosmanoglu 2004). The next parts of this paper investigate the influence of these parameters and their adjustments.

\section{Calibration data}

The first two parameters of IFM ( $\mathrm{S}_{\max }$ and $\gamma$ ) can be estimated by observation, but some minor adjustments may be required to make the IFM accurate. The angle of influence $\gamma$ typically depends on the geological context of the overburden and is roughly constant for similar mines at a given site (Haciosmanoglu 2004). The maximal subsidence is also roughly constant for similar mines in a given site. For critical and super critical cases, i.e., for ratios of the mining width $\mathrm{W}$ by depth $\mathrm{H}$ greater than $2 * \tan \gamma$, the maximal subsidence can be assessed with Equation 4 (Sheorey el al. 2000; Saeidi 2010). For example, in the case of the NCB mining context, the critical case corresponds to cases with $\mathrm{W} / \mathrm{H}=1.4$.

$$
S_{\max }=K \times O \times \tau
$$

Where $\mathrm{O}$ is the thickness of the excavated layer, $\tau$ is the extraction ratio $(\mathrm{O} * \tau$ is then the equivalent thickness of the void) and $\mathrm{K}$ is an empirical coefficient. The $\mathrm{K}$ coefficient varies with the mining context but is roughly constant for mines excavated at the same site with similar 
conditions. For example, a typical value of 0.9 is used for coal mines in England, and 0.68 is used for Provence Coal mines in France (Aissaoui 1999). The other parameters (function $\mathrm{K}_{\mathrm{z}}$ and adjustments) must also be adapted for each context. Two kinds of references curves can be used to find the best value and type of these parameters or function $\left(S_{\max }, \gamma\right.$ and $\left.\mathrm{K}_{z}\right)$. These curves use normalised variables and are typically used in mining engineering because they are representative of the global context of a given site. They can be constructed from empirical data describing previous subsidences that were collected from a given site. Figure 2 illustrates the geometry of the mine panel and the typical shape of such references curves (Alejano, Ramírez-Oyanguren, and Taboada 1999; Al Heib, Linkov, and Zoubkov 2000).

The first curve (Figure $2 b$ ) is the ratio $S_{m} / S_{\max }$ versus the ratio $W / H$, where $S_{m}$ is the maximum subsidence at the center, $\mathrm{S}_{\max }$ is the maximum possible subsidence for critical or supercritical cases, and $\mathrm{W}$ and $\mathrm{H}$ are, respectively, the width and the depth of the mining surface. These curves can be obtained when a set of historical subsidences are available for a given site. They show a typical evolution of $\mathrm{S}_{\mathrm{m}} / \mathrm{S}_{\max }$ from 0 to 1 for the greatest values of $\mathrm{W} / \mathrm{H}$. As can be seen in Figure $2 \mathrm{~b}$, the value of subsidence for a minimum value of the ratio $\mathrm{W} / \mathrm{H}$ is negligible, which is realistic. So the IFM must be modified to reproduce this phenomenon. A possible mathematical equation for this curve uses a tangent hyperbolic function (Equation 5) (Sheorey el al. 2000).

$$
\frac{s_{m}}{s_{\max }}=a\left[b+\tanh \left(c \times \frac{W}{H}+d\right)\right]
$$

Where $a, b, c$ and $d$ are empirical coefficients that must be calculated with observational data for each mining site. The second curve (Figure 2c) is the normalised subsidence profile, i.e., the ratio $\mathrm{S}(\mathrm{x}) / \mathrm{S}_{\mathrm{m}}$ versus $\mathrm{X} / \mathrm{H}$, where $\mathrm{S}(\mathrm{x})$ is the subsidence at abscise $\mathrm{X}$ from the origin above the center of the mine. 


\section{The effects of different parameters of IFM methods the subsidence prediction}

In the following subsection a rectangular mine panel with a length of $1200 \mathrm{~m}$ and a width of 200 $\mathrm{m}$ is used to assess the subsidence. The influence angle is set to $35^{\circ}$, and the depth is set equal to $140 \mathrm{~m}$, which corresponds to a critical case. $\mathrm{O}$ is equal to $1.5 \mathrm{~m}$, with an extraction ratio $\tau$ of $100 \%$.

\section{Influence of the influence function $\mathrm{Kz}$}

Numerous influence functions (IFs) exist in the literature that are either derived from empirical observations or based on theoretical assumptions. All IFs have the same aim: accurately model the subsidence of the ground surface (Table 1). Nevertheless, they show significant differences in

ground profiles because of geological setting variations in each mining field. The selection of a particular IF, therefore, needs to be validated by a comparison with previous existing subsidences to take into account the geological conditions of the studied site. Table 1 presents different IFs used in different countries for subsidence prediction (Singh 1992).

In Table $1, \mathrm{r}$ is the horizontal distance between the considered point at the surface and the elementary mining area (Figure 1a), $\mathrm{R}$ is the radius of the critical area of excavation (Equation 6) and $\gamma$ is the influence angle.

$R=H \times \tan \gamma$

To investigate the influence of the IF, the two reference curves previously described $\left(\mathrm{S}_{\mathrm{m}} / \mathrm{S}_{\max }\right.$ versus $\mathrm{W} / \mathrm{H}$ and $\mathrm{S} / \mathrm{S}_{\mathrm{m}}$ versus $\left.\mathrm{x} / \mathrm{H}\right)$ are plotted for the theoretical case considered for the investigations. W is constant and different values of $\mathrm{H}$ are considered to investigate different ratios of $\mathrm{W} / \mathrm{H}$. It can be noted that the results are exactly the same if $\mathrm{H}$ is constant and $\mathrm{W}$ varies.

Results of the normalised maximum subsidence in the center of the panel $\left(\mathrm{S}_{\mathrm{m}} / \mathrm{S}_{\mathrm{max}}\right)$ versus $\mathrm{W} / \mathrm{H}$ ratio are presented in Figure 3a. The figure shows that the results significantly depend on the 
chosen IF. The three IFs of Sheorey (2000), Litwiniszyn (1957, with n=1) and Beyer (1945) give similar results with small values of $\mathrm{S}_{\mathrm{m}} / \mathrm{S}_{\max }$ compared to those of other functions. Conversely, the Sann (1949), Kochmanski (1959) and Bals (1932) IFs give similar results with higher values of $\mathrm{S}_{\mathrm{m}} / \mathrm{S}_{\max }$. For a mine depth greater than $142 \mathrm{~m}(\mathrm{~W} / \mathrm{H}>1.4)$, the mine is supercritical, and the maximum subsidence $\mathrm{S}_{\mathrm{m}}$ reaches the maximum theoretical value $\left(\mathrm{S}_{\max }\right)$.

Table 1. Presentation of different influence functions used in different mining contexts (Singh 1992; Sroka and Hejmanowski 2006].

\begin{tabular}{|c|c|}
\hline Reference & Function \\
\hline Bals (1932) & $K_{z}(r)=\frac{1}{\pi[\operatorname{Sin\gamma } \operatorname{Cos} \gamma+\{(\pi / 2)-\gamma\}]} \cdot \frac{R^{3} \operatorname{Tan}^{3} \gamma}{r\left(r^{2}+R^{2} T a n^{2} \gamma\right)^{2}}$ \\
\hline Beyer (1945) & $K_{z}(r)=\frac{3}{\pi R^{2}}\left[1-\left(\frac{r}{R}\right)^{2}\right]^{2}$ \\
\hline Sann (1949) & $K_{z}(r)=\frac{n \cdot 2^{(1 / n)}}{\pi \cdot R \cdot \Gamma(1 / 2 n) \cdot r} e^{\left[-4\left(\frac{r}{R}\right)^{2 n}\right]}$ \\
\hline Litwiniszyn (1957) $\mathrm{n}=1$ or $\mathrm{n}=3$, in relation to strata conditions \\
\hline $\begin{array}{c}\text { Ehrhardt and Sauer } \\
\text { (1961) }\end{array}$ & $K_{z}(r)=\frac{n}{R^{2}} e^{-n \pi\left(\frac{r}{R}\right)^{2}}$ \\
\hline $\begin{array}{c}\text { Sheorey et al. (2000) } \\
\text { with } \mathrm{n}=1 \text { or } \mathrm{n}=2, \text { in relation to strata conditions }\end{array}$ \\
\hline $\begin{array}{c}\text { Kochmanski (1959) } \\
K_{z}(r)=\frac{4.6}{\pi R^{2}} e^{\left[-4.6\left(\frac{r}{R}\right)^{2}\right]}\end{array}$ \\
\hline $\left.\left.\begin{array}{c}K_{z}(r)=\frac{7}{R^{2}} e^{\left(-6.65 \frac{r}{R}\right)} \\
\hline R^{2}\end{array}\right] 1+\operatorname{Cos} \frac{\pi \cdot r}{R}\right]$ \\
\hline
\end{tabular}


The results of the normalised subsidence $\left(\mathrm{S} / \mathrm{S}_{\mathrm{m}}\right)$ versus $\mathrm{X} / \mathrm{H}$ ratio are presented in Figure $3 \mathrm{~b}$ for the rectangular case considered for the investigations. The results show significant differences among the different IFs with a similar conclusion to that for Figure 3a. The three IFs of Sheorey (2000), Litwiniszyn (1957, with $n=1)$ and Beyer (1945) give similar results with a subsidence profile flatter than for the three IFs of Sann, Kochmanski and Bals. All of the IFs give a middle subsidence $\left(\mathrm{S} / \mathrm{S}_{\mathrm{m}}=0.5\right)$ for $\mathrm{X} / \mathrm{H}=0.7$. This point corresponds to the position of the mine edge (Singh 1992).

In conclusion, the choice of IF appears to be a first alternative to adjust IFM to observations. In particular, for a given value of the angle of influence, IFs can control the value of the maximal subsidence for sub-critical cases and the flatness of the subsidence without any change in the subsidence extension.

\section{Influence of the mine length}

The mine polygon length may have a significant influence on the reference curves. For this investigation, the reference case of a rectangular mine is used with different values of the length between $200 \mathrm{~m}(\mathrm{~L}=\mathrm{W})$ and $1200 \mathrm{~m}(\mathrm{~L}=6 \mathrm{~W})$. The IF of Litwiniszyn $(1957$, with $\mathrm{n}=1)$ is considered, and the results are plotted in Figure 4. Figure 4a shows the effects of the L/W parameter on the maximal subsidence above the center of the mining panel. The influence of the $\mathrm{L} / \mathrm{W}$ ratio appears to be negligible for values greater than 4 but is significant for the smallest values around 1. Figure $4 \mathrm{~b}$ shows the influence of $\mathrm{L} / \mathrm{W}$ on the normalised subsidence profile prediction. It is observed that this parameter has no effect. 


\section{Influence of the influence angle $\gamma$}

Another important parameter for subsidence prediction by IFM is the influence angle $\gamma$. This parameter mostly depends on the overburden geology and its geotechnical characteristics. It may also depend on the mining exploitation method, and its value is typically between 5 and $40^{\circ}$ (Haciosmanoglu 2004; Saeidi 2010).

To investigate the influence of $\gamma$, the two reference curves previously described are plotted for the rectangular case with $\gamma$ between 10 and $40^{\circ}$. The IF of Litwiniszyn (1957, with $\left.n=1\right)$ is considered, and the results are plotted in Figure $5 \mathrm{a}$ and $\mathrm{b}$. It can be observed (Figure 5a) that the maximal subsidence $S_{\mathrm{m}}$ increases with small values of $\gamma$, which is consistent with the calculation of the radius of the critical area of excavation (Equation 6). For the smallest value of $\gamma$, R becomes small, and the value of $\mathrm{W} / \mathrm{H}$ corresponding to a critical case is also reduced. The influence of $\gamma$ appears to be greater than the influence of the other parameters.

The influence of $\gamma$ on the subsidence profile (Figure 5b) is also significant. As $\gamma$ increases, the subsidence profile becomes flatter. Moreover, the horizontal extension of the mine subsidence logically increases as $\gamma$ increases.

\section{Influence of the area reduction}

A typical problem of IFM is predicting subsidence above the excavation boundaries. Basic use of IFMs gives a subsidence of $50 \%$ of $\mathrm{S}_{\max }$ for critical and supercritical cases (Figure $3 \mathrm{~b}$ ). Observations show that this value is generally overestimated (Haciosmanoglu 2004). Another problem of IFMs is predicting the subsidence for small values of the $\mathrm{W} / \mathrm{H}$ parameter. The influence of excavations with very small values of $\mathrm{W} / \mathrm{H}$ is typically negligible. For example, Figure $2 \mathrm{~b}$ shows 
a context in which no subsidence is expected to occur for values of $\mathrm{W} / \mathrm{H}$ less than 0.2 . However, this behaviour is not reproduced by IFMs that predict a significant subsidence for small values of W/H (Figure 3a, Figure 4a, Figure 5a).

To solve the first problem, Whittaker and Reddish (1989) proposed decreasing the dimensions of the mine. They introduced a coefficient of dimensions reduction CDR (Figure 6 and Equation 7).

$$
C D R=\Delta X / H
$$

Where $\Delta \mathrm{X}$ is the reduction of the mine dimensions that must be considered and $\mathrm{H}$ is the mine depth (Figure 5a). They evaluate the variability of this coefficient between 0 and 0.14 by comparing the results of the IFM with the results of NCB (National Coal Board 1975). Figure 6c shows the effect of a CDR of 0.14 over the subsidence profile prediction. It is clear that this coefficient is equal to the horizontal shifting of the normalised subsidence profile that is required to get a realistic ratio of subsidence above the excavation boundaries (Figure 6c).

The second problem can be solved in the same way; the coefficient can be estimated by comparing the initial result of the IFM with observational results. The CDR parameter is then equal to half the value of $\mathrm{W} / \mathrm{H}$ under which the subsidence is negligible (Figure $6 \mathrm{~b}$ ). Consequently, the CDR can be calculated by considering one of the two reference curves with comparison of observational results. The two estimations may be slightly different, and a compromise must be found.

In this paper and to investigate the influence of the CDR coefficient, the two reference curves previously described are plotted in Figure 6 for the theoretical and reference cases without considering $\mathrm{CDR}(\mathrm{CDR}=0)$ and considering a value of $\mathrm{CDR}=0.14$. The Litwiniszyn (1957, with 
$\mathrm{n}=1$ ) IF is considered. It can be observed (Figure $6 \mathrm{~b}$ ) that the maximum subsidence $\mathrm{S}_{\mathrm{m}}$ decreases as $\mathrm{CDR}$ increases, and the subsidence prediction is more realistic with $\mathrm{CDR}=0.14$ because the subsidence is reduced to zero for a $\mathrm{W} / \mathrm{H}$ ratio less than 0.28 . Figure $6 \mathrm{c}$ shows the effect of CDR on the subsidence profile prediction. It is observed that the subsidence value of a given point at the

surface decreases as CDR increases. Consequently, the subsidence ratio $\mathrm{S} / \mathrm{S}_{\mathrm{m}}$ over the boundary of the mine is then reduced from 0.5 to 0.3 , which is in agreement with typical empirical data.

\section{$4 \quad$ Methodology for adjusting the IFM at each mining site}

As explained in the previous section, applying IFM requires modifications for each mining site. It is then possible to estimate the subsidence, and the IFM appears to be operating for this purpose because of the different adjustments that are possible with these methods. In this part of the paper, a methodology is defined for adjusting IFM methods and is tested and validated on a case study (a coal mine in France).

\section{Description of the methodology}

As explained in sections 2 and 3, there are several parameters that can modify IFM results. The first parameter is the $\mathrm{K}$ coefficient (Equation 4) that is used to calculate the maximal subsidence in the super-critical case. Other parameters are the influence function $\left(\mathrm{K}_{\mathrm{z}}\right)$, the influence angle $(\gamma)$ and the coefficient of dimensions reduction (CDR). These parameters are used to modify the IFM. Moreover, these parameters are characteristic of each mining region for which the geological and mining context is equivalent. Their value may then be considered constant in a given region.

We have developed a methodology based on subsidence empirical data to calibrate IFM for subsidence prediction. The algorithm of this methodology is shown in Figure 7. The algorithm 
requires using the two reference curves for the maximum subsidence prediction and the subsidence profile prediction. The first step consists of choosing a set of input data that are representative of a mining region: the influence angle $\gamma$, the maximum subsidence for critical or super-critical cases $\left(\mathrm{S}_{\max }\right)$ or the corresponding $\mathrm{K}$ coefficient according to Equation 4 and the two reference curves with empirical data. The second step considers a theoretical case (W, L, H, O) that represents mines of the studied region to define the reference curves of the site. The third step requires calculating the CDR parameter according to one or two of the reference curves by comparing the theoretical and empirical curves. In the fourth step, the appropriate influence function is chosen by comparing the empirical reference curves with the two reference curves calculated with the theoretical case defined in the second step, for different IFs. The fifth step consists of adjusting the influence angle. If the results are acceptable in terms of the initial angle of influence and the chosen IF, no adjustment is required. Conversely, if discrepancies are significant, the initial influence angle must be adjusted. The sixth and final step consists of validating all of the adjustments by testing the final method with a specific case. If the prediction is comparable with the observations, adjustments are then validated, and the method is used to predict future subsidences in the studied mining region.

\section{Application and validation of the methodology}

\section{Application and validation of the methodology for England coal mines}

In this part, subsidence prediction given by NCB (National Coal Board 1975) is used to generate and validate IFM adjustments. A rectangular panel with a length $\mathrm{L}$, a width $\mathrm{W}$ and a depth $\mathrm{H}$ is considered. The NCB results are used for several cases that differ in geometry, mine length or depth(National Coal Board 1975). We choose one case for the adjustments and the others for 
validation.

\section{a) Application}

The two reference curves of NCB (National Coal Board 1975) for a mine panel with a width of $200 \mathrm{~m}$, a length of $1200 \mathrm{~m}$, a depth of $142 \mathrm{~m}$ and an influence angle of $35^{\circ}$ are presented in the Figure 8. The first curve is $\mathrm{S}_{\mathrm{m}} / \mathrm{S}_{\max }$ versus the $\mathrm{W} / \mathrm{H}$ ratio for a mine panel with a ratio $\mathrm{L} / \mathrm{W}=4$, and the second curve is the subsidence $\mathrm{S} / \mathrm{S}_{\mathrm{m}}$ versus the $\mathrm{X} / \mathrm{H}$ ratio for a mine panel with a ratio $\mathrm{W} / \mathrm{H}=1.4$, (Al Heib, Linkov, and Zoubkov 2000) that corresponds to a critical case. This setup corresponds to steps 1 and 2 of the methodology.

The third step is calculating the CDR coefficient. This parameter can be calculated separately with both observational reference curves and is equal to 0.11 when considering the maximal subsidence curve (Figure 8a) and 0.14 when considering the subsidence profile curve (Figure $8 \mathrm{~b}$ ). The two values are very close, and a mean value of $\mathrm{CDR}=0.12$ is considered for this analysis.

The fourth step consists of choosing an appropriate IF. The references IFs in Table 1 are tested to find the best IF. The results of the comparison between several IFs and the two NCB reference curves are plotted in Figure 9a and Figure 9b for four IF. The Sann's IF appears to be the best function that fits the two reference curves well. Consequently, this function is chosen for the prediction of subsidence with IFM. The fifth step of the methodology is not always necessary. It consists of making a small change in the influence angle value. Minor discrepancies between the Sann's and NCB curves in Figure 9 should be corrected by reducing the influence angle, as shown in Figure 5. In this example, the initial value of the influence angle is $35^{\circ}$ and small variations are considered with $\gamma=32$ or 40 . The results are shown in Figure 10a and Figure 10b, respectively. It 
is observed that a value of $\gamma=32$ leads to the best results for subsidence prediction. Finally, a CDR value of 0.12 , the Sann's IF and an influence angle equal to $32^{\circ}$ are chosen to assess subsidence for mines consistent with $\mathrm{NCB}$ cases.

\section{b) Validation}

Adjustments are validated by comparing the subsidence profiles predicted by NCB with the calibrated IFM for different mine geometries. Two cases are considered: a super-critical case (W/H $=2.0)$ and an under-critical case $(\mathrm{W} / \mathrm{H}=0.6)$. The geometric characteristics of the mine panel are $\mathrm{W}=200 \mathrm{~m}, \mathrm{~L}=1200 \mathrm{~m}$ and $\mathrm{H}=100 \mathrm{~m}$ for the super-critical case and $\mathrm{H}=333 \mathrm{~m}$ for the under-critical case. All of the previous adjustments are considered, i.e., a CDR equal to 0.12 , an influence angle of $32^{\circ}$ and Sann's IF. The results are shown in Figure 11. Empirical and theoretical curves are mostly comparable, and the adjustments are validated.

\section{Application and validation of the methodology for the Provence Coal Basin in France}

The Gardanne colliery (Provence) is located in south-eastern France. The last panel of the lignite deposit reaches a maximum depth of $1250 \mathrm{~m}$. An important feature of the mine is the exceptional stiffness of the overburden and sidewalls that correspond to limestone with uniaxial strength equal to $140 \mathrm{MPa}$, which is the main factor in the occurrence of rock bursts. The mining method of all the exploitations was room and pillar and then long wall. The Provence Coal Basin is characterised by an influence angle of about $35^{\circ}$ and a $\mathrm{K}$ value of 0.68 for the determination of the maximum subsidence (Equation 4), i.e., the maximum subsidence for a super-critical case is $70 \%$ of the mining opening. The IFM is applied to and validated on two sectors of the mine. IFM adjustments were chosen by comparing the results with empirical subsidence data from the Arbois Sud mine 
(Figure 12). The methodology was then validated with empirical subsidence data from the Estaque Sud mine.

\section{a) Application of IFM method to the Arbois Sud mine}

According to the first step of the proposed methodology (Figure 7), the input data are the thickness of coal $(2.85 \mathrm{~m})$, the influence angle $\left(35^{\circ}\right)$ and the $\mathrm{K}$ coefficient $(0.68)$. The curve of $\mathrm{S}_{\mathrm{m}} / \mathrm{S}_{\max }$ versus $\mathrm{W} / \mathrm{H}$ was obtained from empirical data from the Provence. Equation 5 is used to fit the curve to the empirical data (Figure 12).

According to the second step of the methodology, a theoretical configuration must be defined that corresponds to a rectangular sector with comparable dimensions to those of the panels extracted in the Provence Basin. Extraction panels observed in the Provence Basin typically have a width between 200 and $240 \mathrm{~m}$ and a length two to five times greater than the width (Aissaoui 1999). Consequently, a width of $220 \mathrm{~m}$, a length of $660 \mathrm{~m}$, an opening of $2.85 \mathrm{~m}$ and a depth of $1000 \mathrm{~m}$ are considered for the theoretical configuration.

According to the third step of the methodology, the first curve (Figure 11) is used to calculate the CDR value. This value is found to be equal to 0.09 for the Provence Coal Basin. The second curve appears more difficult to use to assess CDR because the profile is not purely perpendicular to the mine boundary. Moreover, existing data are not sufficient to plot perpendicular profiles.

The fourth step of the methodology consists of choosing the best IF. Consequently, the different IFs described in Table 1 are compared with the two empirical reference curves. The results are shown in Figure 13a and b. The Litwiniszyn $(n=1)$ IF appear to gives very good and comparable results for the prediction of maximal subsidence, and the Litwiniszyn IF is selected. 
The fifth step of the methodology is improving the subsidence prediction after the influence angle is adjusted. For the case of the Arbois Sud mine, several values of the influence angle are considered, and a final value of $40^{\circ}$ is selected. The results of this analysis are shown in Figure $14 a$.

Finally, the characteristics of IFM adjustments are as follows:

the CDR coefficient is 0.09

$>$ the IF is the Litwiniszyn function with $\mathrm{n}=1$ (Table 1)

the influence angle is $40^{\circ}$

\section{b) Validation of the modified IFM with the Estaque Sud mine in Provence}

To validate the adjustments, the Estaque Sud sector is considered. The opening of this mine is 2.85 $\mathrm{m}$, and the depth is $1000 \mathrm{~m}$. The comparison between the empirical subsidence and calculated subsidence with the modified IFM is shown in Figure 14b. The results of the modified IFM validate the adjustments at a majority of the measurement points, but a noticeable difference between the IFM results and the observational results still remains on a few points to the right of the polygon or section (Figure 14b). These differences also appear in the predictions obtained using other

methods (Aissaoui 1999). Therefore, this problem probably does not depend on the method of subsidence prediction but may depend on the geological or mechanical characteristics of the ground in this part of the studied region. For example, by considering some heterogeneity of the geological conditions, the influence angle on the right of the polygon could be less than $40^{\circ}$.

\section{Conclusion}

In this paper, a methodology is developed to adjust IFMs based on empirical data. A sensitivity analysis is performed first to investigate the effects of each parameter and adjustment. The results of this analysis can be summarised as follows: 
Many influence functions (IF) are available in the literature. Analysis shows that the subsidence prediction results significantly depend on the chosen IF.

The results show that the maximum subsidence depends on both the $\mathrm{W} / \mathrm{H}$ and $\mathrm{L} / \mathrm{W}$ ratios. Moreover, the effect of the length variation becomes negligible for $\mathrm{L} / \mathrm{W}$ ratios greater than 4 but is significant for values around 1 .

$>$ The influence angle may significantly influence the results, and a variation of $5^{\circ}$ may lead to significant variations in the subsidence prediction.

$>\mathrm{CDR}$ of mine panels is used to adjust the value of subsidence above the border of the mine panels. This correction is also consistent with the required adjustment to avoid any subsidence for very small ratios of $\mathrm{W} / \mathrm{H}$. A method is described to calculate this coefficient.

Finally, a methodology to adjust IFMs for each mining site is developed and tested with the data from the NCB (National Coal Board 1975) and empirical data from the Provence Coal Basin in France. For these cases, some adjustments are first calculated for a given case and then validated with another case before possible use in the studied region. A comparison of the results of the modified IFM and observational data show that good agreement is possible. However, some differences between the results of this method and observed data may subsist, as for other methods of subsidence prediction, because of the great number of uncertainties or heterogeneities and the complex mechanical behaviour of rocks and soils. However, the IFMs are mostly effective for mines with complex geometry. Moreover, this method makes a three-dimensional prediction of the subsidence and the calculation of the horizontal displacements and associated strain possible.

\section{References}

Aissaoui, K. 1999. "Amélioration de la prévision des affaissements dans les mines à l'aide des approches empiriques, numériques et analytiques." $\mathrm{PhD}$ thesis, Institut national polytechnique de Lorraine (INPL), Nancy, France, https://hal-ineris.archives-ouvertes.fr/ineris-

00976142/document. 
Alejano, L. R., P. Ramírez-Oyanguren and J. Taboada. 1999. "FDM predictive methodology for subsidence due to flat and inclined coal seam mining." International Journal of Rock Mechanics and Mining Sciences 36 (4):475-491, doi:10.1016/s0148-9062(99)00022-4.

Al Heib, M., A.M. Linkov and V.V Zoubkov. 2006. "On numerical modeling of subsidence induced by mining." Proceedings of the ISRM Regional Symposium EUROCK, Espoo/FINLAND.

Coulthard, M.A., and A.J Dutton. 1988. Numerical modelling of subsidence induced by underground coal mining." The 29th US Symposium on Rock Mechanics (USRMS), June 1315, Minneapolis, MN: Balkema.

Deck, O., T. Verdel and R. Salmon. 2009. "Vulnerability Assessment of Mining Subsidence Hazards." Risk Analysis 29 (10):1381-1394, doi:10.1111/j.1539-6924.2009.01238.

Diao, X., K. Wu, D. Zhou and L. Li. 2016. "Integrating the probability integral method for subsidence prediction and differential synthetic aperture radar interferometry for monitoring mining subsidence in Fengfeng, China." J. Appl. Remote Sens. 10, 016028. Haciosmanoglu, M.E. 2004. "Development of a subsidence model for Çayirhan Coal Mine." MSC thesis. Middle east technical university, Turky, https://etd.lib.metu.edu.tr/upload/12605481 /index.pdf .

Hongdong, F., L. Lu and Y. Yahui. 2018. "Method Combining Probability Integration Model and a Small Baseline Subset for Time Series Monitoring of Mining Subsidence." Remote Sens. 10, 1444; doi:10.3390/rs10091444.

Merad, M. M., T. Verdel, B. Roy and S. Kouniali. 2004. "Use of multi-criteria decision-aids for risk zoning and management of large area subjected to mining-induced hazards." Tunnelling and Underground Space Technology 19 (2):125-138, doi:10.1016/s0886-7798(03)00106-8.

National Coal Board. 1975. Subsidence engineering handbook. National coal board: Mining Department, London.

Ren, G., D. J. Reddish and B.N. Whittaker, 1987. "Mining subsidence and displacement prediction using influence function methods." Mining Science and Technology, 5(1):89-104. Saeidi, A., O. Deck, and T. Verdel. 2009. "Development of building vulnerability functions in subsidence regions from empirical methods."Engineering Structures 31 (10):2275-86. Saeidi, A., O. Deck, and T. Verdel. 2012. "Development of building vulnerability functions in subsidence regions from analytical methods." Géotechnique 62 (2):107-20.

Saeidi, A., O. Deck, M. Al Heib, T. Verdel. 2015. "Development of a damage simulator for the probabilistic assessment of building vulnerability in subsidence areas. " International Journal of Rock Mechanics and Mining Sciences, 73:42-53.

Sheorey, P. R., J. P. Loui, K. B. Singh and S. K. Singh. 2000. "Ground subsidence observations and a modified influence function method for complete subsidence prediction." International Journal of Rock Mechanics and Mining Sciences 37(5):801-18.

Singh, M., 1992. Mine subsidence, SME Mining Engineering Handbook: SME, pp 938-971.

Sroka, A. and R. Hejmanowski. 2006. Subsidence prediction caused by the oil and gas development. Paper presented at the 3rd IAG / 12th FIG Symposium, Baden.

Toraño. J, Rodríguez R. Ramírez-Oyanguren, P. 2000. "Probabilistic analysis of subsidenceinduced strains at the surface above steep seam mining ." International Journal of Rock Mechanics and Mining Sciences 37, (7): 1161-1167.

Whittaker, B.N., and D.J. Reddish. 1989. Subsidence: Occurrence, Prediction and Control.: Elsevier, Amsterdam. 


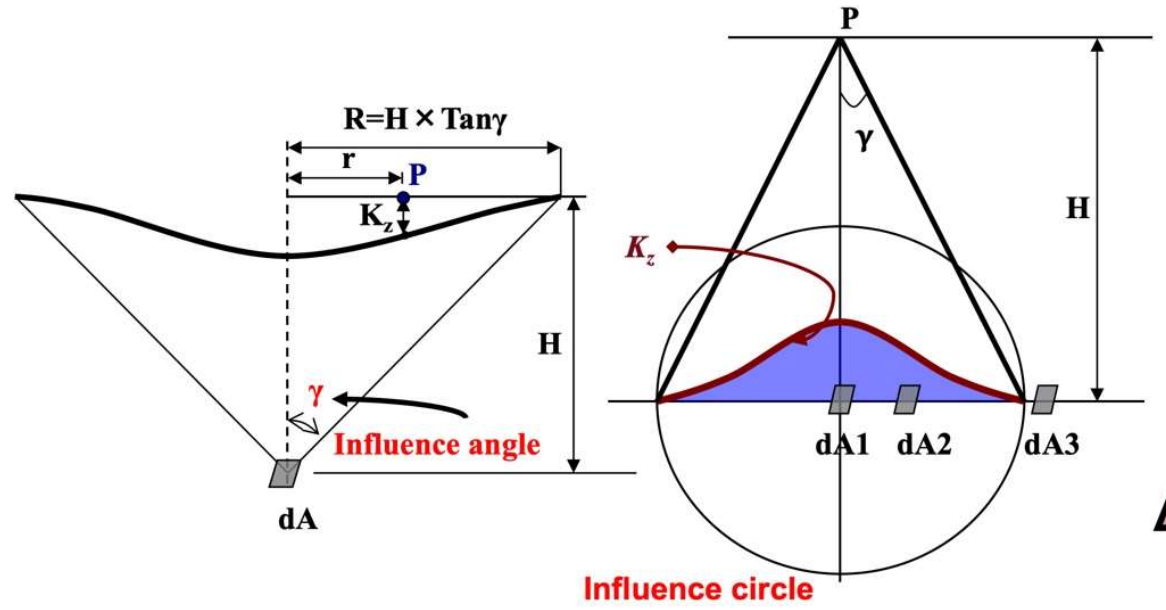

(a) (b)

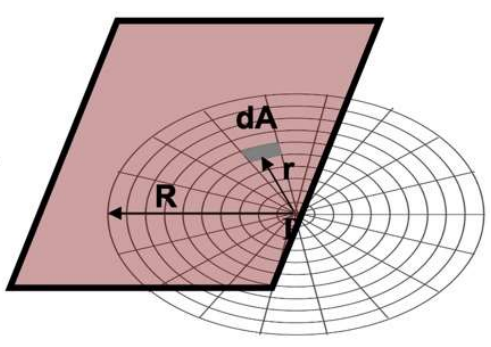

(c)

Fig. 1. a) Principles of the influence function method. A infinite mining element $\mathrm{dA}$ at depth $\mathrm{H}$ creates an elementary trough at the surface. b) Illustration of the influence of elementary area $\mathrm{dAi}$ for the subsidence of a given point $\mathrm{P}$ on the surface. (c) Calculation of subsidence due to each sector dA.

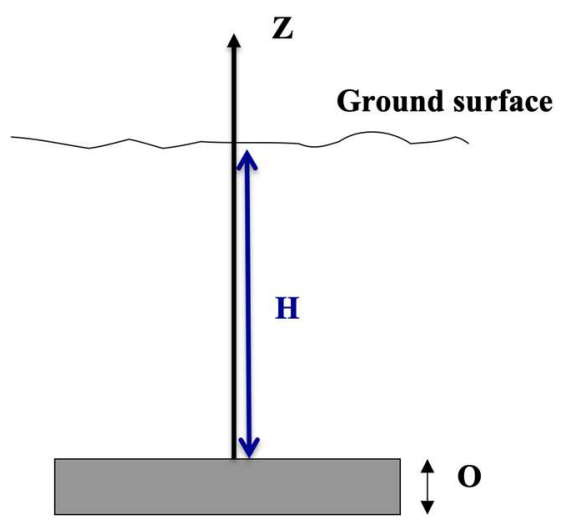

$\mathbf{L}$

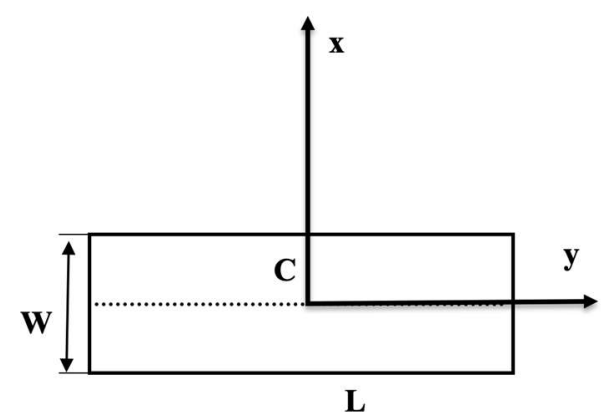

a) 


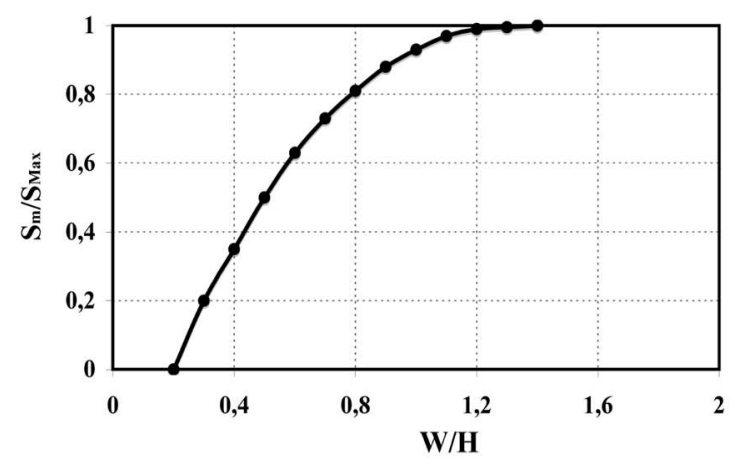

(b)

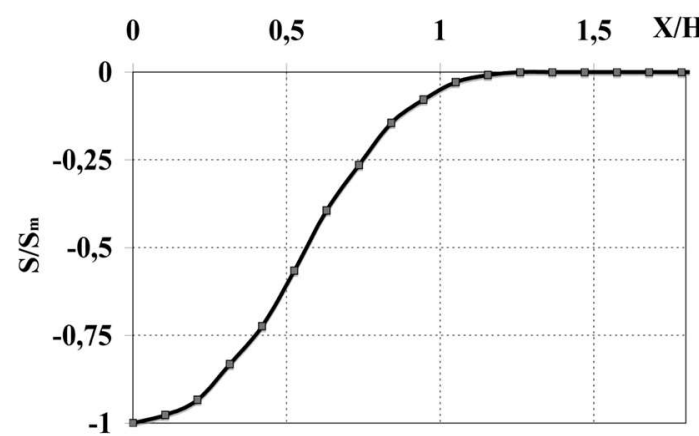

(c)

Fig. 2. (a) Vertical section of the mine and overburden and the plan of a rectangular mining panel; b) Normalised maximal subsidence in relation to the excavation width-by-depth ratio. c) Normalised subsidence profile over a horizontal-and-radial section. 


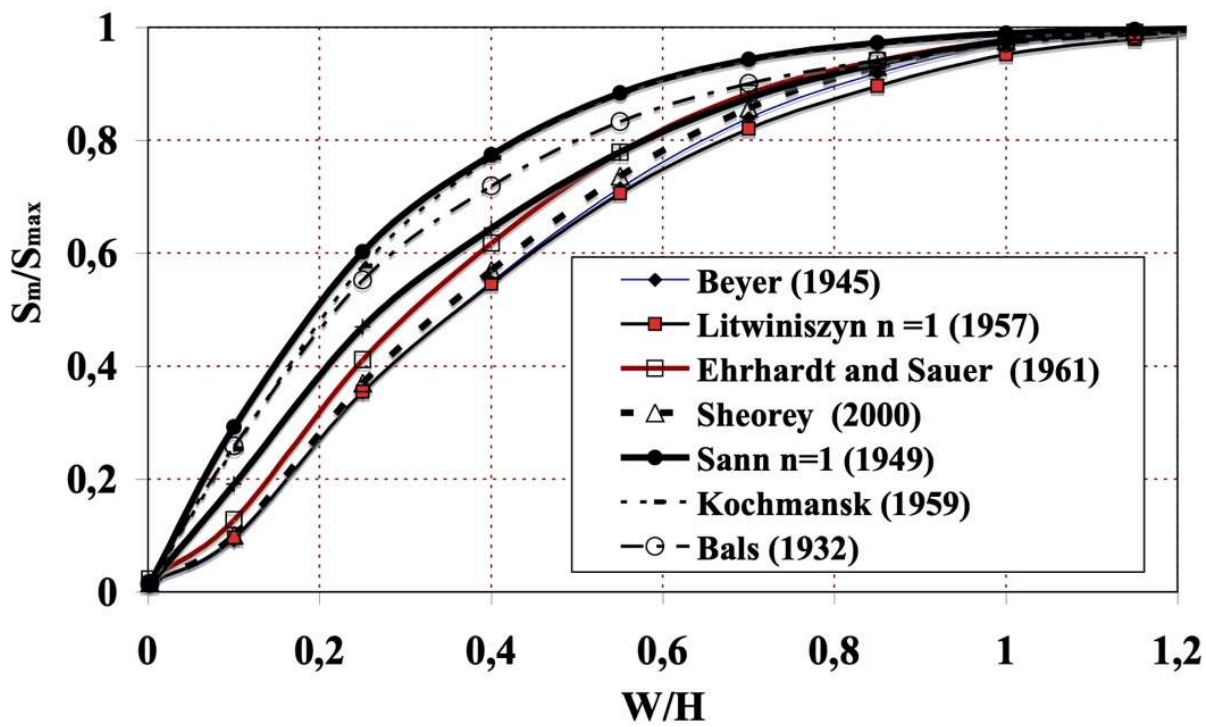

(a)

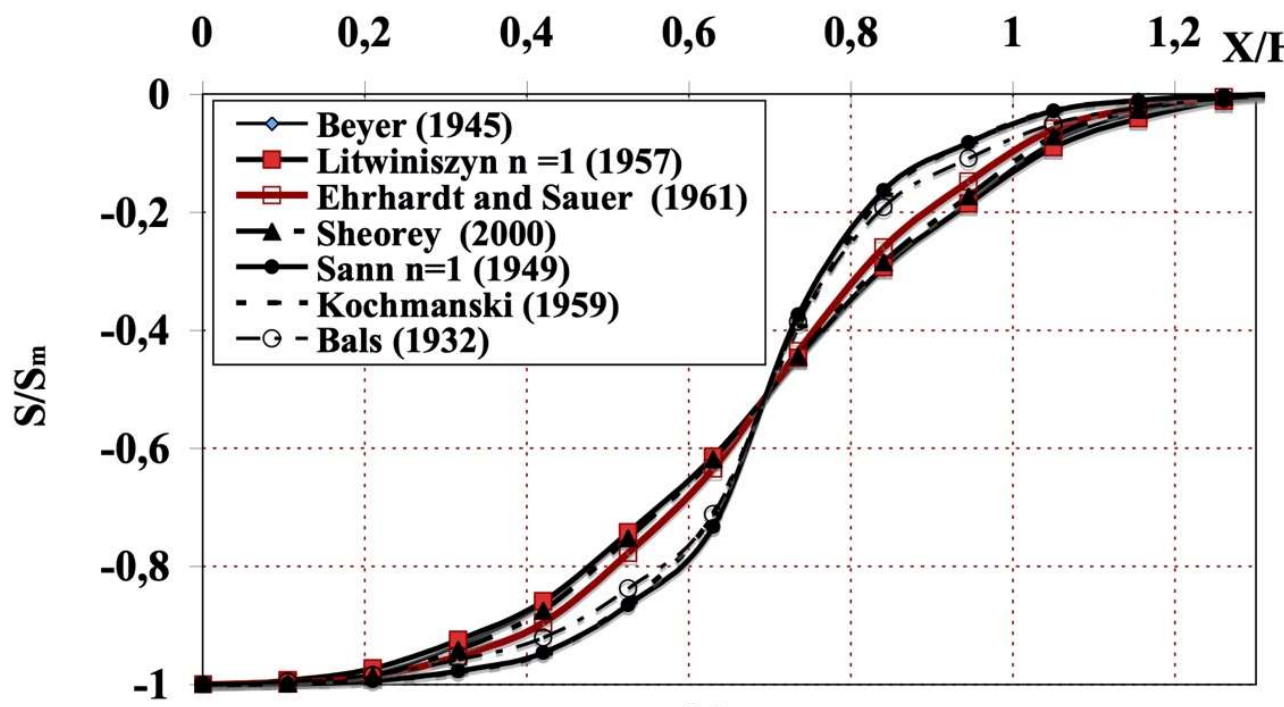

(b)

Fig. 3. Effects of influence functions on the maximum subsidence prediction for different ratios $\mathrm{W} / \mathrm{H}$. 


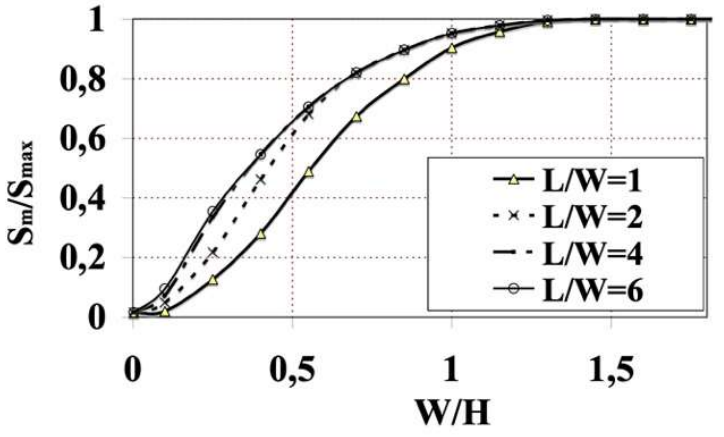

(a)

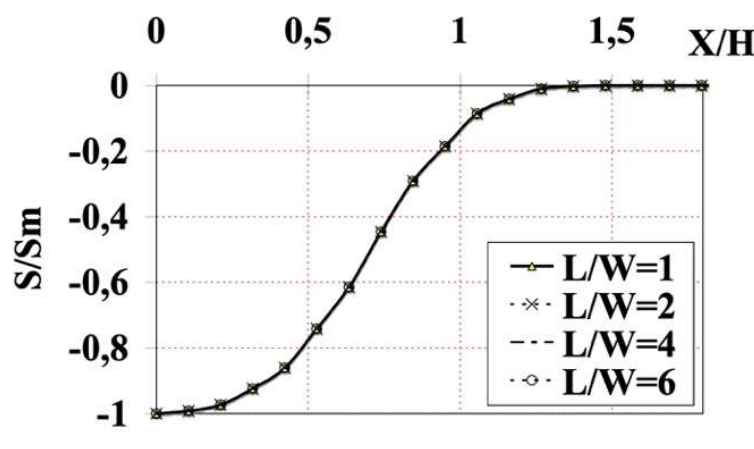

(b)

Fig. 4. Effect of L/W ratio: (a) on the maximum subsidence prediction (b) on the subsidence profile prediction.

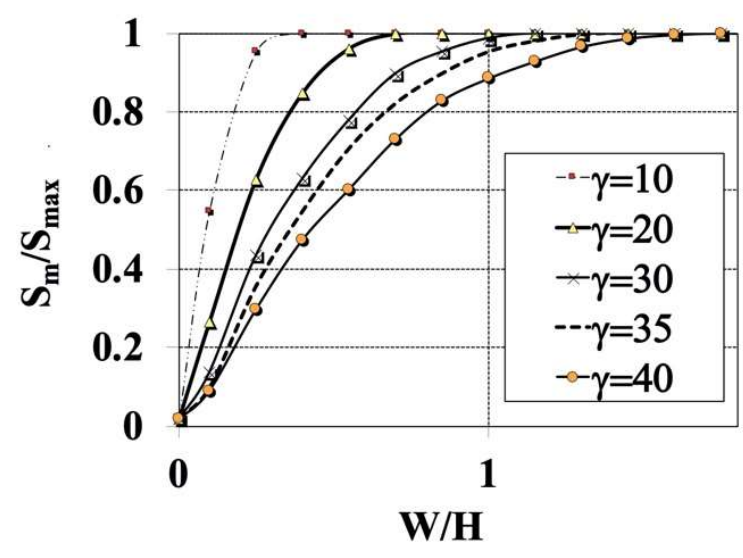

(a)

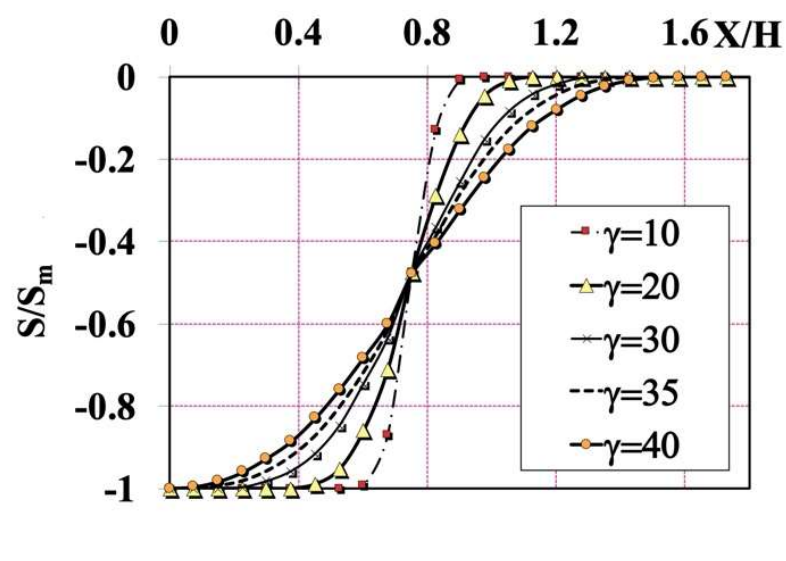

(b)

Fig. 5. Effect of the influence angle (a) on the maximal subsidence prediction and (b) on the subsidence profile prediction. 


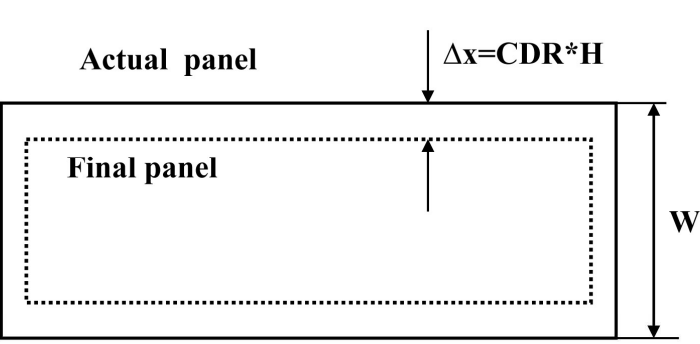

(a)

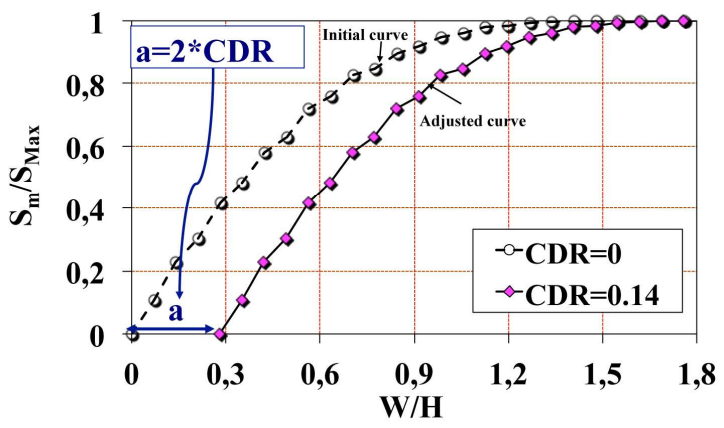

(b)

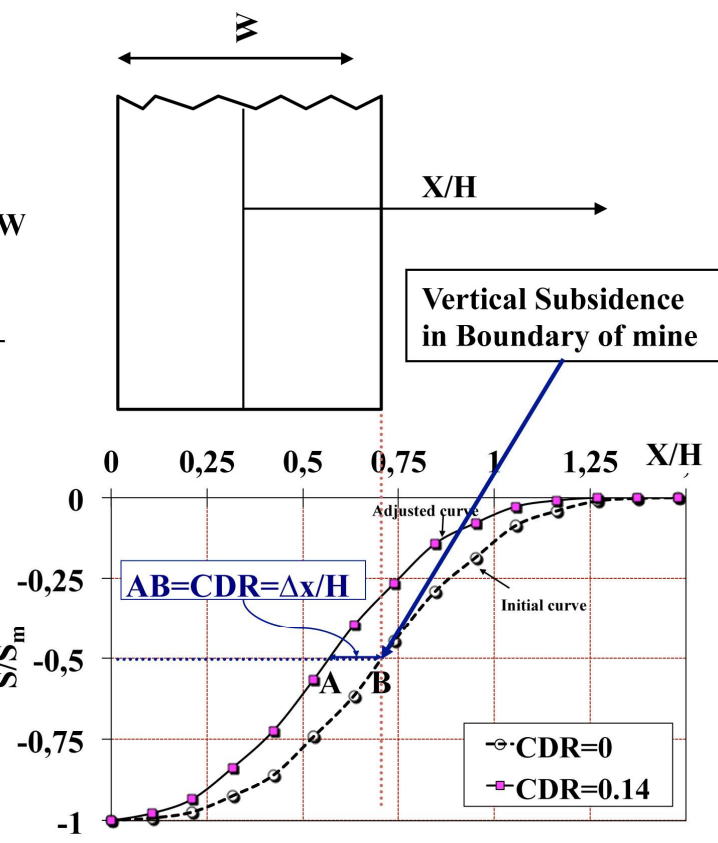

(c)

Fig. 6. a) Definition of the coefficient dimension reduction (CDR) and effect of the CDR (b) on the maximal subsidence prediction and (c) on subsidence profile prediction.

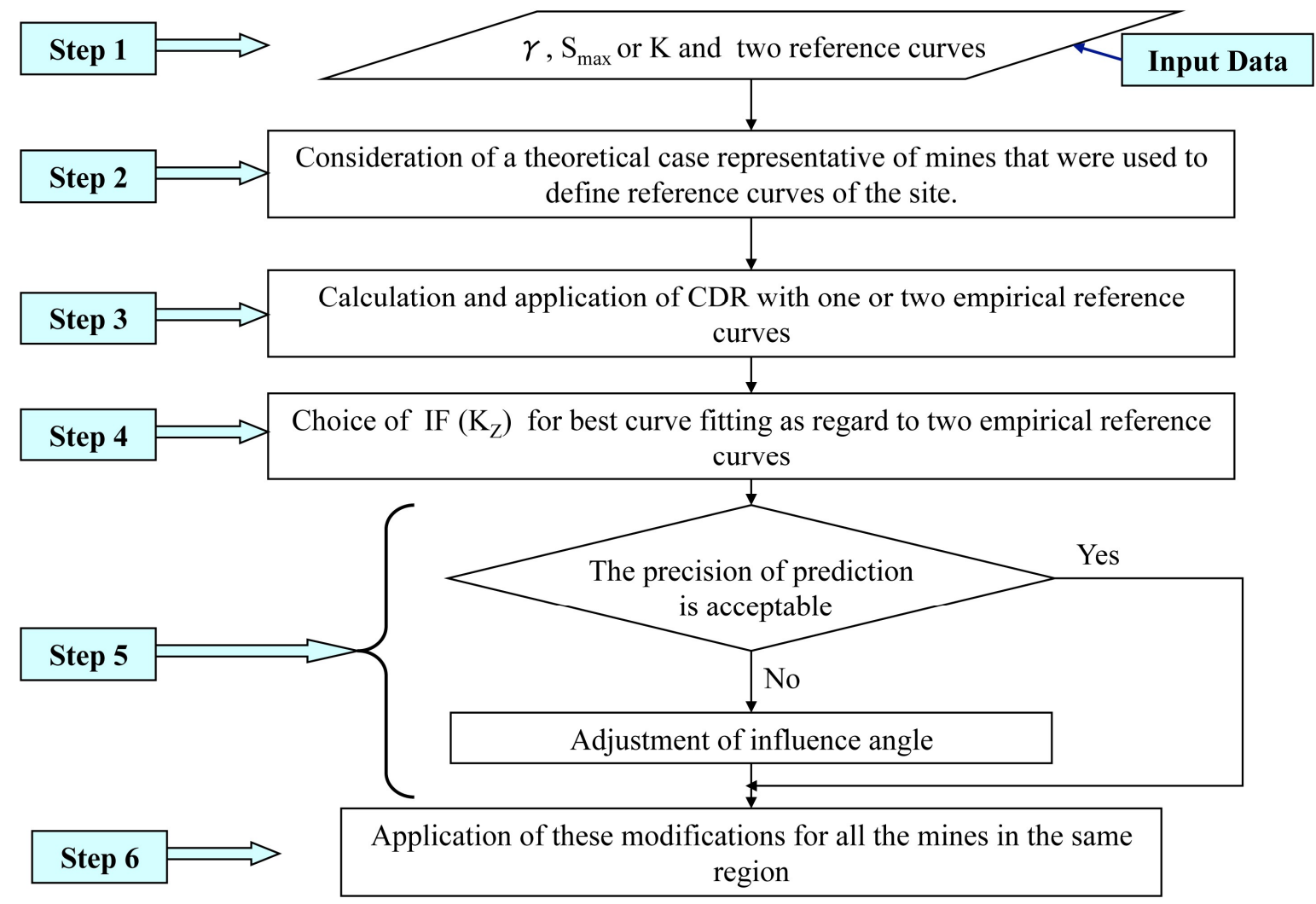


Fig. 7. Methodology for adjusting the IFM for each mining site.

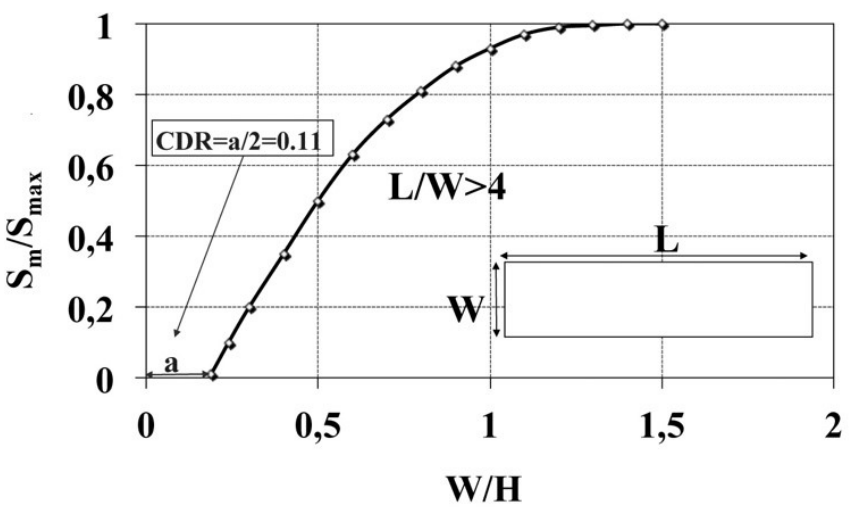

(a)

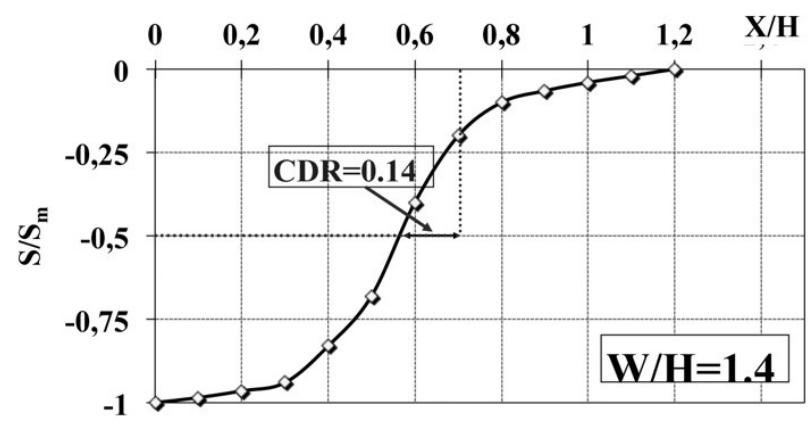

(b)

Fig. 8. Two reference curves from NCB (1975) for rectangular panels [14].

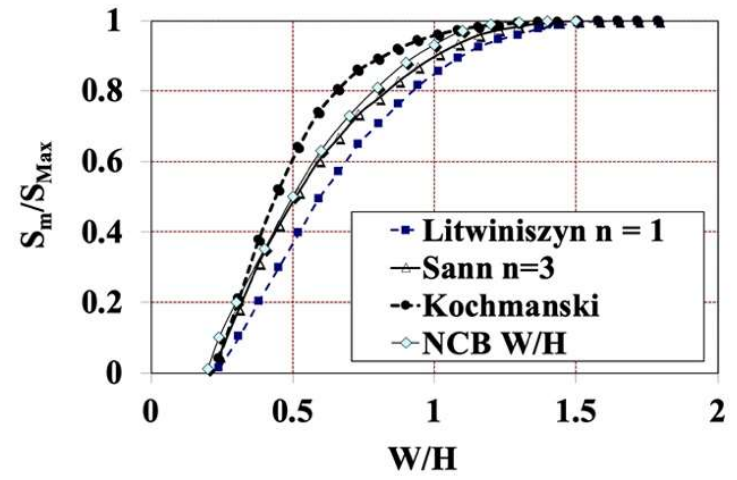

(a)

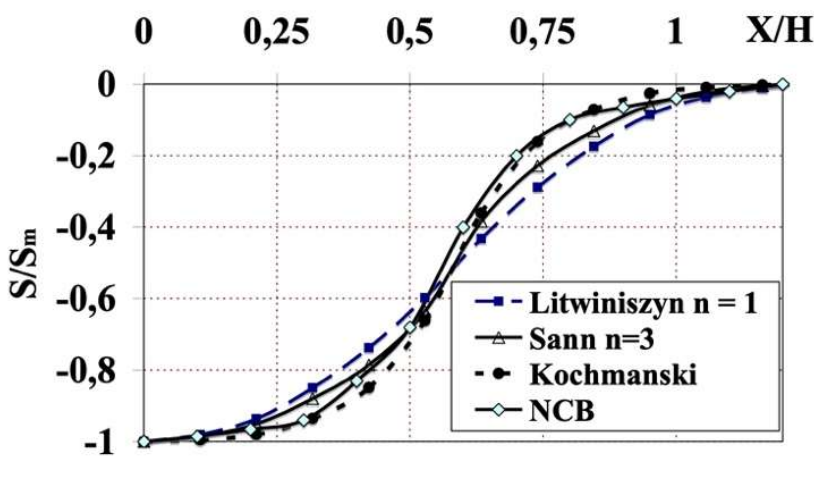

(b)

Fig. 9. Comparison between theoretical curves by IFM and the empirical curves of NCB for different IF.

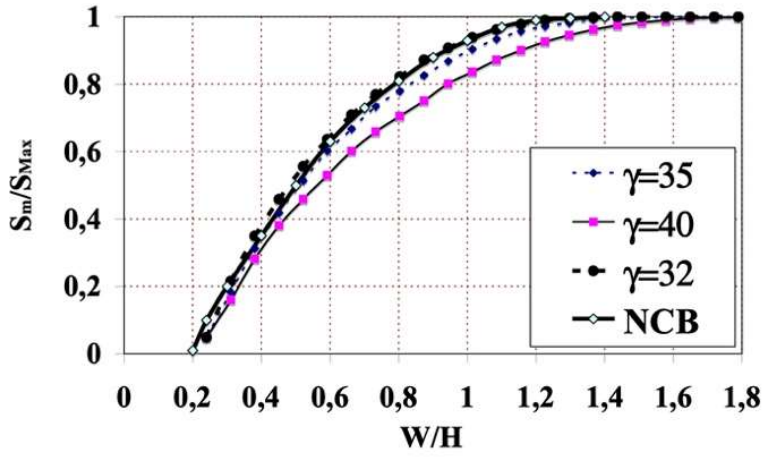

(a)

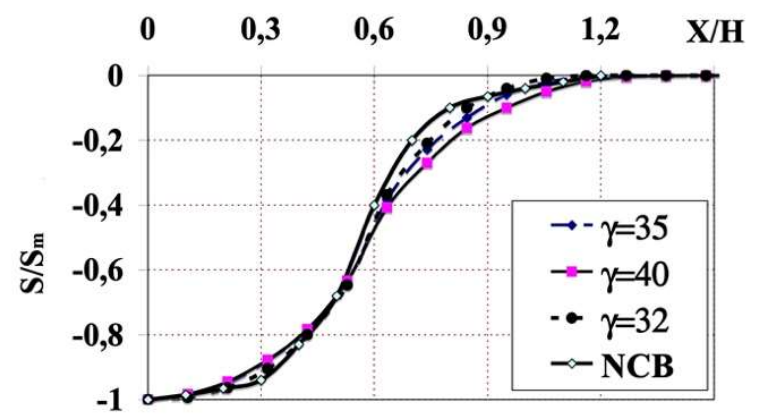

(b) 
Fig. 10. Effect of the final adjustment of the influence angle.

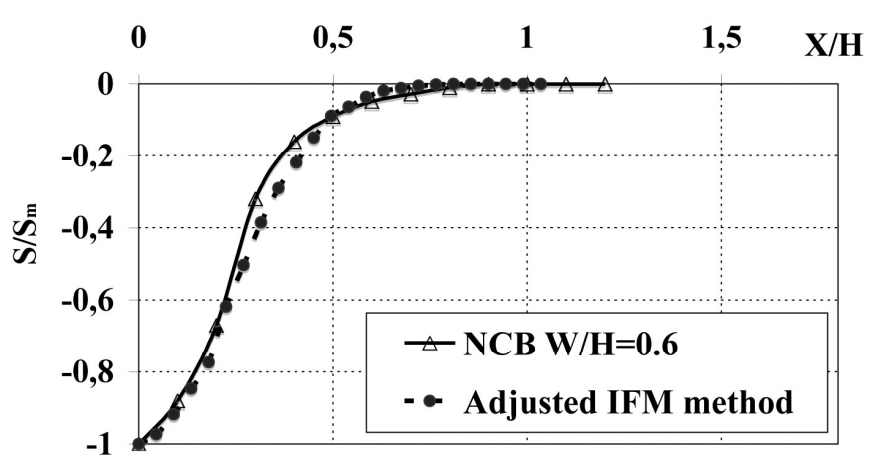

(a)

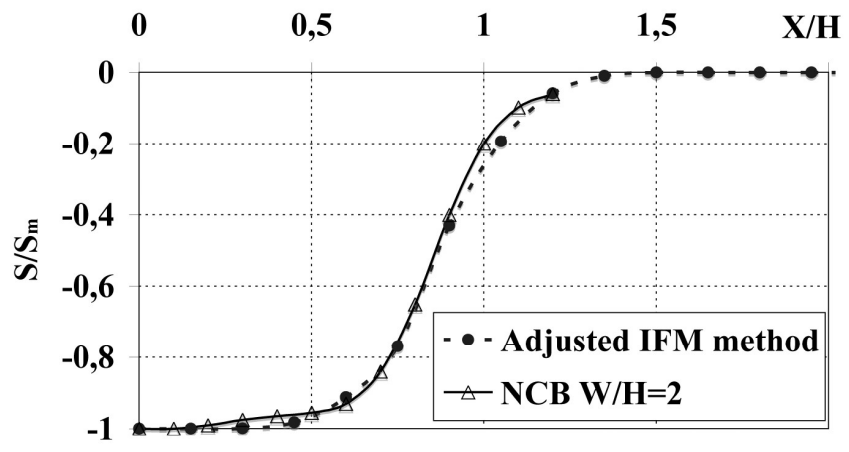

(b)

Fig. 11. Validation of the IFM adjustments for the NCB: a) under-critical case and b) supercritical case.

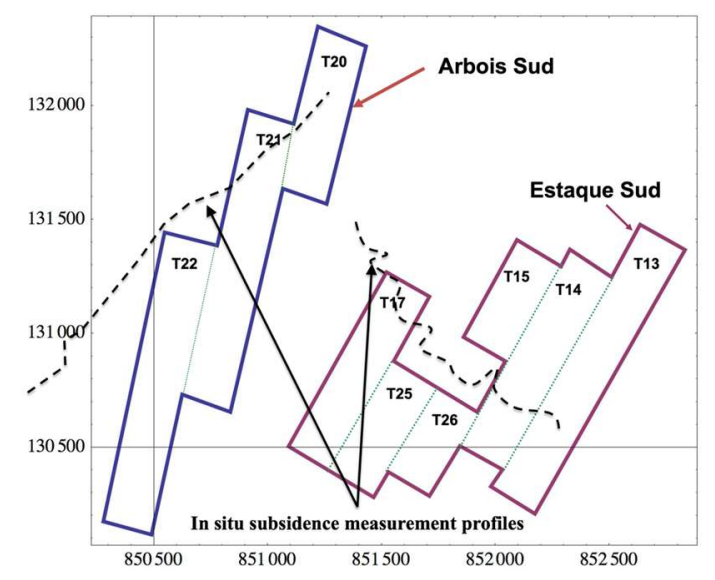

(a)

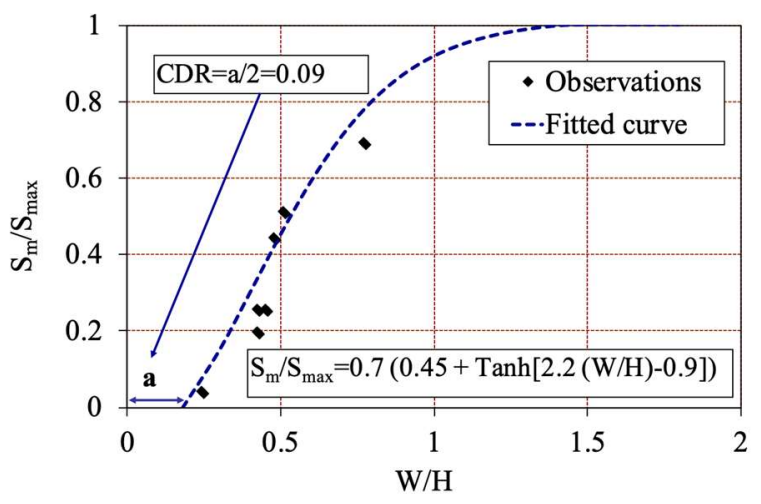

(b)

Fig. 12. a) In situ subsidence measurement profile for Arbois and Estaque Sud mines and b) empirical values of $\mathrm{Sm} / \mathrm{Smax}$ and curve fitting for calculation of CDR (Aissaoui 1999). 


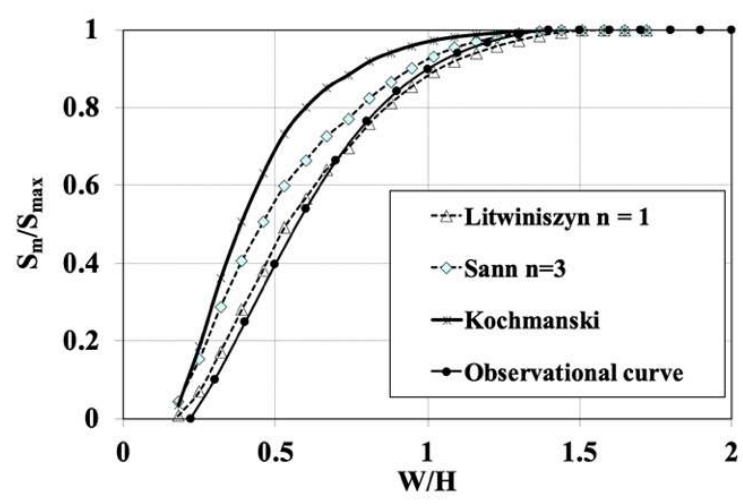

(a)

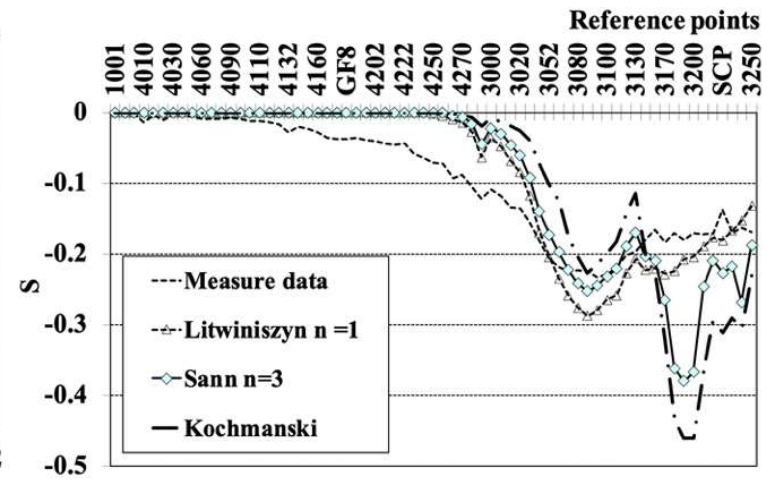

(b)

Fig. 13. Comparison of empirical references curves for the Provence Coal Basin with results of IFM.

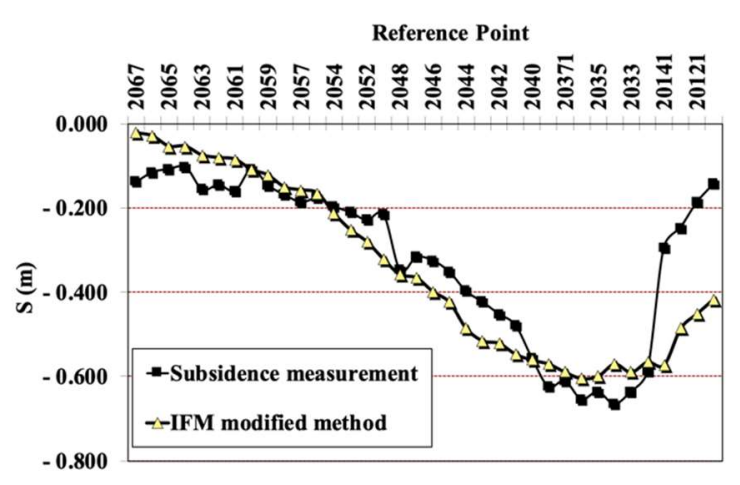

(a)

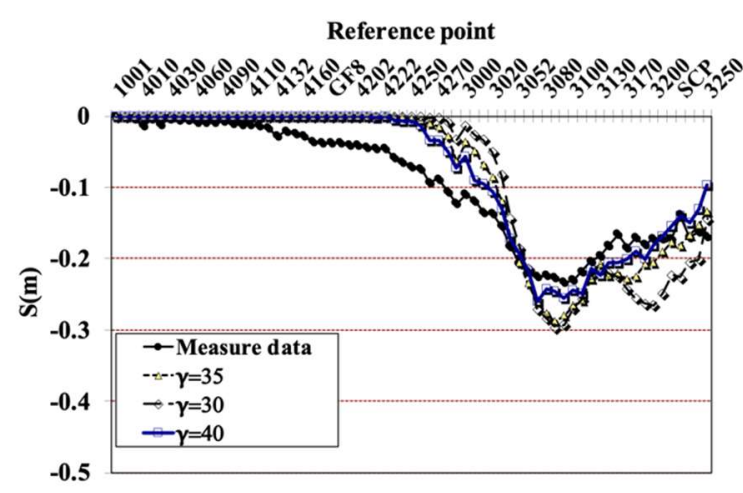

(b)

Fig. 14. a) Adjustment of the influence angle and comparison with the subsidence profile of the south Arbois mine and b) Comparison between the empirical subsidence data above the Estaque Sud mine and subsidence calculated with the modified IFM. 